\title{
Investigation and Analysis on the Popularization of Fitness Sports among Urban and Rural Residents in Gansu
}

\author{
Songbai Zhang \\ Economics and Management College, Longdong University, Qingyang, Gansu
}

Email:gww2008ok@126.com

Keywords: Gansu, residents, fitness, analysis

Abstract: the urban and rural residents sports popularization survey data were classified and the survey of each index were accounted for the calculation in Gansu, draw the proportion of the pie chart, and the proportion of cases were analyzed, the analysis results of sports popularization is an objective reflect in Gansu, provide valuable policy basis to further promote the national fitness campaign.

\section{Introduction}

In order to urban and rural residents in Gansu sports popularization have an objective understanding, to further promote the national fitness campaign to provide policy basis, from March 2017 to July, the research group conducted a sample survey of urban and rural residents in Gansu province to participate in fitness activities, the survey area is covered in Gansu, Lanzhou, Jinchang, Baiyin, Tianshui, Zhangye, Jiuquan (including Dunhuang), Pingliang, Qingyang, Dingxi, Longnan, Dunhuang.

The questionnaire contains 15 questions, 85 options (part of the problem can be selected). The training of investigators 43, 1600 questionnaires, 1300 questionnaires were collected, after each screening, screening out 1056 valid questionnaires.

\section{Displayed separately statistical data}

Table 1 a survey of education accounting analysis

\begin{tabular}{lll}
\hline & number & proportion \\
\hline Above college degree & 457 & $43.3 \%$ \\
Senior high school (technical secondary school) & 267 & $25.3 \%$ \\
Junior middle school & 173 & $16.4 \%$ \\
Primary school & 110 & $10.4 \%$ \\
Below primary school & 49 & $4.6 \%$
\end{tabular}

Table 2 an analysis of occupation proportion of respondents

\begin{tabular}{lll}
\hline & number & proportion \\
\hline Administrative institutions, enterprise leaders & 107 & $10.1 \%$ \\
Professional and technical personnel & 162 & $15.3 \%$ \\
Clerks and related personnel & 78 & $7.4 \%$ \\
Commercial and service personnel & 138 & $13.1 \%$
\end{tabular}


Table 3 an analysis of the proportion of subjects who received physical education

\begin{tabular}{lll}
\hline & number & proportion \\
\hline During school & 490 & $26.7 \%$ \\
Work unit & 237 & $12.9 \%$ \\
Community & 234 & $12.8 \%$ \\
Newspapers, networks, televisions & 449 & $24.5 \%$ \\
Relatives and friends, colleagues & 424 & $23.1 \%$ \\
Sum & 1834 & $100 \%$ \\
\hline
\end{tabular}

Table 4 an analysis of developing a good habit of exercise habits accounting

\begin{tabular}{lcc}
\hline & number & proportion \\
\hline Want & 858 & $81.3 \%$ \\
Don't want & 198 & $18.7 \%$
\end{tabular}

Table 5 an analysis of developing the exercise habit of accounting

\begin{tabular}{lcc}
\hline & number & proportion \\
\hline Yes & 638 & $61.8 \%$ \\
No & 394 & $38.2 \%$ \\
Sum & 1032 & $100 \%$
\end{tabular}

Table 6 an analysis of the proportion of people with exercise habits in the family, relatives and friends of the respondents

\begin{tabular}{lcc}
\hline & number & proportion \\
\hline $1-2$ & 289 & $27.4 \%$ \\
$3-4$ & 367 & $34.7 \%$ \\
$5-6$ & 212 & $20.1 \%$ \\
$7-8$ & 91 & $8.6 \%$ \\
Above 9 & 97 & $9.2 \%$ \\
Sum & 1056 & $100.0 \%$ \\
\hline
\end{tabular}

Table 7 an analysis of the main entertainment modes of respondents

\begin{tabular}{lcc}
\hline & number & proportion \\
\hline Athletic sports & 303 & $25.6 \%$ \\
Fancies of men of letters to read & 110 & $9.3 \%$ \\
Watch TV & 317 & $26.8 \%$ \\
Surf the Internet & 326 & $27.6 \%$ \\
Mahjong, poker & 127 & $10.7 \%$ \\
Sum & 1183 & $100 \%$ \\
\hline
\end{tabular}

Table 8 an analysis on the proportion of objects participating in physical exercise

\begin{tabular}{lcc}
\hline & number & proportion \\
\hline Increase physical strength, endurance & 302 & $25.4 \%$ \\
Prevent disease and prolong life & 223 & $18.7 \%$ \\
Relax your body and relax & 346 & $29.1 \%$ \\
Slimming, bodybuilding & 228 & $19.2 \%$ \\
Entertainment making friends & 91 & $7.6 \%$ \\
Sum & 1190 & $100 \%$ \\
\hline
\end{tabular}


Table 9 an analysis of the proportion of sports items at ordinary times

\begin{tabular}{lcc}
\hline & number & proportion \\
\hline Walking and running & 811 & $39.7 \%$ \\
Swimming, rowing & 30 & $1.5 \%$ \\
Mountain climbing & 193 & $9.4 \%$ \\
Ride a bike & 167 & $8.2 \%$ \\
Single parallel bars, lifting weights & 44 & $2.2 \%$ \\
Badminton & 192 & $9.4 \%$ \\
Basketball & 197 & $9.6 \%$ \\
Football & 34 & $1.7 \%$ \\
Table Tennis & 79 & $3.9 \%$ \\
Other ball games & 27 & $1.3 \%$ \\
All kinds of Wushu & 36 & $1.8 \%$ \\
Various dances & 111 & $5.4 \%$ \\
All kinds of Gymnastics & 35 & $1.7 \%$ \\
Horse racing Diaoyang wrestling and other special & 15 & $0.7 \%$ \\
Other recreational activities & 73 & $3.5 \%$ \\
Sum & 2044 & $100 \%$ \\
\hline
\end{tabular}

Table 10 an analysis of the proportion of weekly exercise frequency

\begin{tabular}{lcc}
\hline & number & proportion \\
\hline 1 & 213 & $20.2 \%$ \\
2 & 310 & $29.4 \%$ \\
3 & 259 & $24.5 \%$ \\
4 & 113 & $10.7 \%$ \\
5 & 161 & $15.2 \%$ \\
Sum & 1056 & $100 \%$ \\
\hline
\end{tabular}

Table 11 an analysis of the proportion of primary exercise time

\begin{tabular}{lcc}
\hline & number & proportion \\
\hline 0.5 & 298 & $28.2 \%$ \\
1 & 436 & $41.3 \%$ \\
1.5 & 129 & $12.2 \%$ \\
2 & 115 & $10.9 \%$ \\
Above 2 & 78 & $7.4 \%$ \\
Sum & 1056 & $100 \%$ \\
\hline
\end{tabular}

Table 12 an analysis of intensity ratio of fitness exercise

\begin{tabular}{lcc}
\hline & number & proportion \\
\hline Moderate exercise (low intensity) & 607 & $57.5 \%$ \\
Total sweating (moderate intensity) & 337 & $31.9 \%$ \\
Sweating profusely (high strength) & 96 & $9.1 \%$ \\
Challenge limit (ultra high strength) & 16 & $1.5 \%$ \\
Sum & 1056 & $100 \%$ \\
\hline
\end{tabular}


Table 13 an analysis of the proportion of different fitness places

\begin{tabular}{lcc}
\hline & number & proportion \\
\hline Streets, roads & 360 & $27.7 \%$ \\
Park & 262 & $20.1 \%$ \\
Cultural Square & 181 & $13.9 \%$ \\
Residential area & 102 & $7.8 \%$ \\
Wilderness & 46 & $3.5 \%$ \\
club & 44 & $3.4 \%$ \\
Gymnasium & 199 & $15.3 \%$ \\
Natural mountains and rivers & 38 & $2.9 \%$ \\
Others & 70 & $5.4 \%$ \\
Sum & 1302 & $100 \%$ \\
\hline
\end{tabular}

Table 14 Subjects continued to exercise for the time

\begin{tabular}{lcl}
\hline & number & proportion \\
\hline 1 & 358 & $33.9 \%$ \\
$2-5$ & 457 & $43.3 \%$ \\
$5-10$ & 164 & $15.5 \%$ \\
$10-20$ & 38 & $3.6 \%$ \\
Above 20 & 39 & $3.7 \%$ \\
Sum & 1056 & $100 \%$
\end{tabular}

Table 15 an analysis of the proportion of professional guidance in fitness exercise

\begin{tabular}{lll}
\hline & number & proportion \\
\hline Yes & 354 & $33.5 \%$ \\
No & 702 & $66.5 \%$ \\
Sum & 1056 & $100 \%$
\end{tabular}

\section{Statistical data analysis}

In Table 1, the sample selection is random, but the statistical results of sample survey secondary education accounted for $68.6 \%$. is to cooperate with the investigation by the high level of education of residents, good information collection. In the following analysis should give full consideration to the sample of different educational level accounted for factor.

In table 2, occupation classification design reference categories: the national occupation classification. The economic development is relatively backward in Gansu, social development retardation, there are a lot of people have no professional expertise, job mobility, intermittent time, so choose "other persons" accounted for 33.6\%, and this choice is consistent with the actual situation investigation personnel.

In table 3, all kinds of schools open system of sports theory course and practice course, is the basis of fitness education television, network, and newspapers is the main channel for modern people to obtain information, relatives and friends are the main influence groups. Work units and residential community sports publicity, guidance, education accounted for a relatively small, were $12.9 \%$ and $12.8 \%$, these two aspects of sports work in a large space for development.

In table 4, want to develop a good habit of exercise residents accounted for $81.3 \%$ of the respondents, Gansu urban and rural residents fitness consciousness has been awakened. But there are still $18.7 \%$ of the residents do not want to form a good habit of exercise, this proportion can not be ignored, the reasons need professional research.

In table 5, the survey has developed a fitness exercise habits accounted for $61.8 \%$, this is a very 
gratifying situation. The dance for joy but also to see there are $38.2 \%$ of the respondents want to develop exercise habits but do not develop exercise habits, we need to seriously study the reasons of them, and some are willing to help the masses gradually develop exercise habits.

In table 6, the survey of the family, relatives, the number of fitness habits circle of friends, 3-6 options accounted for $54.8 \%$, which shows the good atmosphere of urban and rural residents fitness preliminary form in Gansu.

In Figure 7, the main entertainment survey of TV and the Internet accounted for $54.4 \%$, in line with the current status of time consumption, sports accounted for $27.6 \%$, and the proportion of high growth potential is also great.

In table 8, the survey of sports participation main purpose is to increase strength, longevity, diet, fitness, entertainment, relax, active muscles, consistent with the mass fitness movement we advocate purpose.

In table 9, it is worth for sports analysis than usually select subjects. Walking, running the highest proportion, accounting for $39.7 \%$, because there is no special requirements on the site, also have no technical content, time at random. Climbing and cycling each accounted for $9.4 \%$ and $8.2 \%$, the basic reason is the same as the badminton and basketball. Accounted for $9.4 \%$ and $9.6 \%$, and the mass sports preferences and traditional sports. It is worth mentioning that the dance accounted for more than 5.4\%, which is consistent is a multi-ethnic province in Gansu, folk dance has a long history, variety, inheritance, carry forward its need. Horse racing wrestling sheep need special environment and characteristics of the project as a professional organization, daily sports only in the pastoral areas have a condition, our statistics is $0.7 \%$, that the national heritage area of these exercise habits.

In table 10, the survey week exercise 2 times, 3 times the number of proportion of the total accounted for 53.9\%, in line with the people of Gansu on sports cognition level, leisure time and sports consumption of the pay.

Table 11 , one hour survey of a sports accounted for more than $41.3 \%$, basically achieve the purpose of fitness, it may be appropriate for longer periods of time. A 0.5 hour exercise accounted for $28.2 \%$, as the fitness movement time is short, can be appropriately extended. A movement of 1.5 to 2 hours of exercise time accounted for $23.1 \%$. The ideal, to gradually increase the proportion.

In table 12, low intensity crowd sports accounted for $89.4 \%$, the appropriate strength, the higher the proportion of sports meet the fitness requirements.

In table 13, respondents choose different fitness venues, street, Park Road accounted for 27.7\%, accounted for $20.1 \%$, the two together accounted for $47.8 \%$ of these venues nearby, convenient, no charge. It is worth noting that the choice of gym population accounted for $15.3 \%$, Gansu high-end fitness groups have form.

In table 14, the survey group continued to exercise 1 to 5 years accounted for $77.2 \%$, indicating: (1) In recent 5 years sports related departments have done a lot of work for the popularization of mass sports very fruitful in Gansu. (2) Urban and rural residents of Gansu province sports consciousness awakening. (3) The popularity of the people of Gansu province fitness into the fast lane, sports facilities need to follow up the software and hardware measures caused the attention of the relevant departments.

In table 15, Gansu residents had little sports instructor guidance, basic is voluntary, conscious, free movement, so some hidden worries: (1) restricted the Gansu mass sports further spread. (2) It is not conducive to the health people's mental health and sports safety. (3) It is not conducive to the development of Gansu the sports industry is not conducive to mining. (4) National traditional sports, promotion and popularization.

\section{Comparison of weekly exercise times between urban and rural residents of different categories}

\subsection{The number of times of exercise has nothing to do with gender}

The analysis shows that: (1) male and female exercise frequency distribution curve trend is 
consistent. (2) the number of weekly exercise accounted for very close. Analysis: sports men and women generally higher level of education, have good occupation and income, both in equal status in the family, most of the common fitness, so the trend and the proportion is very close.

\subsection{There was a similar trend in the number of times of exercise in different education levels}

The analysis shows that: (1) the "primary school" and "junior high school" residents week exercise relatively close to the number of "primary school"; 1 week exercise the highest proportion, "junior high school" line week exercise 2 times the highest proportion; the "high school" and "College and above residents week exercise frequency is close to that of" high school "line 2 times the highest proportion," College and above "line 3 times the highest proportion (2). The same or similar level of education people have similar perceptions of exercise, also have similar movement. (3) of different levels of education in the" 4 times ", showing the lowest point.

\subsection{People of different ages show different laws of motion}

The analysis shows that: (1) "25" and "26 - 35" two lines of similar shape, close to the trend, relatively flat; (2) the "36 - 50" line 2 times up to 31\%, 4 times the lowest $9 \%$, the reason is the state organs, institutions, there is a collective all enterprises in a week, such as political learning, training and other services, from the time occupied a fitness opportunity. (3) "3 high and 2 low 50 - 60 year old phenomenon" line, the general trend of higher, the basic cause of these population age stereotypes, well-to-do, movement formation (4). "60 years old" 4 times the number of people exercise less, and increase the number of weeks of exercise 5 times, reason need further study.

\subsection{Different occupation residents have different laws of movement}

The analysis shows that: (1) "Organs, cause, close to the leading enterprises" and "professional and technical personnel" two lines accounted for close to trend. (2) "Staff" curves from 31\% steep drop to $11 \%$, then to $2.7 \%$, this group of people because of work pressure, less degree of freedom. Most people exercise 2 to 3 times. (3) "Close to the business and service" and "staff" curve trend curve trend. (4) "agriculture and water conservancy staff" week exercise 1 times up to 34.1\% weeks, exercise 2 times to reach 25\%, this part of the staff sports is not regular. (5) "The production of transport equipment operators" week 1 times, 2 times, 3 times the proportion of uniform, flat curve, 4 week exercise proportion suddenly reduced to 4.5\%. (6) "Retirees and housewives" and "other persons" flat curve, uniform distribution, the basic form of law the movement.

\subsection{Most of residents sports week times are similar, there are obvious differences in individual states}

The analysis shows that: (1) the majority of the city is close to the trend curve, indicating that the basic balanced development of residents exercise in Gansu. (2) Residents sports 1-2 times weekly accounted for 78\%, 3 and 5 for 22\% in Zhangye. (3) Residents 3 week exercise 5 times accounted for 84\% in Dunhuang, 12 times the proportion of 16\%. (3) residents exercise 3 times weekly accounted for $85.7 \%$ in Jinchang, 4 week exercise accounted for 0 weeks, exercise 5 times the proportion of $14.3 \%$. (5) 4 times weekly accounted for very low generally.

\section{Acknowledgements}

The paper is one of the 2016 research projects of Gansu sports social science research results. (GST201624)

\section{References}

[1] Xiangrong Liu, Hongbin Li, Zhengwei Gong, query the concept of traditional sports and sports classification [J] Journal of social science o f Hunan Normal University November.2006 volume sixth, 30-50

[2] Guanlong Bao. Introduction to sports [M] • Beijing: Higher Education Press, 1995.

[3] Information on http://www.Olympic.cn

[4] Information on http://www.stats.gov.cn/ 